\title{
Potential manipulations to restore aberrant myelopoiesis: The role of new colony-stimulating factors and other agents
}

JAMES J RUSTHOVEN, MD

\begin{abstract}
JJ Rusthoven. Potential manipulations to restore aberrant myelopoiesis: The role of new colonystimulating factors and other agents. Can J Infect Dis 1992;3(Suppl B):76B-83B. A rapidly growing number of new recombinant human colony-stimulating factors (CSFs) are entering various phases of clinical testing. With the recent approval of granulocyte colony-stimulating factor (G-CSF) and granulocytemacrophage colony-stimulating factor (GM-CSF) for clinical use, newer CSFs will be developed for a widening spectrum of disease states singularly and in combination with other CSFs. Interleukin (IL)-3 is being tested in early clinical trials, and combination studies with G-CSF and GM-CSF are to follow soon. IL-6 presently is in animal model testing, but already shows promise of amplifying the restorative capabilities of IL-3, IL-4, GM-CSF and others. As a single agent, IL-6 may be instrumental in clarifying disease processes and therapeutics in diseases ranging from multiple myeloma to glomerulonephritis. Agents such as WR-2721 which appear to protect early progenitors with or without proliferative effects likely will add another dimension to the therapeutic alternatives for restoring aberrant myelopoiesis. The range of potential clinical application for new CSFs rapidly is expanding beyond oncology to include diseases where infection prevention or therapy against established infection is the prime target of treatment.
\end{abstract}

Key Words: Colony-stimulating factors, Interleukin-3, Interleukin-6, WR-2721

\section{Manipulations susceptibles de restaurer la myélopoïésie aberrante: Le futur rôle des facteurs de stimulation de colonies et autres agents}

RÉSUMÉ: Un nombre croissant de facteurs de stimulation des colonies (CSF) font actuellement l'objet d'essais cliniques. Suite à l'approbation récente des facteurs de stimulation de colonies des granulocytes (G-CSF) et de colonies des macrophages-granulocytes (GM-CSF) pour utilisation en clinique, d'autres CSF qui pourront être utilisés seul ou en combinaison seront mis au point pour traiter un nombre encore plus grand d'affections. L'interleukine-3 (IL-3) est actuellement soumise à une investigation clinique et des études combinant le G-CSF et le GM-CSF suivront sous peu. L'IL-6 est actuellement testêe sur un modèle animal et semblerait notamment majorer les propriétés restauratrices de l'IL-3, de l'IL-4 et du GM-CSF. L'IL-6 pourrait contribuer à mieux faire comprendre le processus pathologique et thérapeutique de diverses affections, du myélome multiple à la glomérulonéphrite. Les substances telles que le WR-2721, qui semblent protéger les cellules souches primitives avec ou sans effets prolifératifs, ajouteront probablement une autre dimension aux possibilités de traitement de la myélopoïés aberrante. La gamme d'applications cliniques potentielles des nouveaux CSF s'étend rapidement au-delà de la cancérologie pour englober les maladies où la prévention et le traitement des infections établies est l'objectif premier.

Hamilton Regional Cancer Centre, Hamilton, Ontario

Correspondence and reprints: Dr James Rusthoven, Hamilton Regional Cancer Centre, 711 Concession Street, Hamilton, Ontario L8V 1C3. Telephone (416) 387-9495 ext 4341 
I 1991, THREE RECOMBINANT HUMAN COLONY-STIMULATINC factors (rhuCSFs) were approved by the Food and Drug Administration in the United States for use in various clinical settings (1). The rapid development of these agents from in vitro testing to standard therapy in just five years typifies the frantic pace at which CSF development is moving forward. The fact that no fewer than 14 recombinant human factors with CSF activity are being developed simultaneously has resulted in a staggering proliferation of studies and growing confusion about the future role of these agents in medical practice.

When granulocyte colony-stimulating factor (G-CSF) and granulocyte-macrophage colony-stimulating factor (GM-CSF) were approved for use as standard therapies early last year, interleukin (IL)-1 (2-4), IL-3 (5) and M-CSF (6) were entering early human clinical trials (Table 1). IL-6 (7), IL-4 (8) and human stem cell factor (9) are in varying phases of animal testing. Soon to follow will be human GM-CSF/IL-3 fusion protein (10), IL-5 (11), -7 (12), -9 (13), - 11 (14) and a recombinant receptor for IL-1, all of which are undergoing preliminary in vitro assessment.

In order to understand how these compounds could find a therapeutic niche in restoring myelopoiesis, a thematic classification of myelopoiesis disorders is useful (Table 2).

Myelosuppression induced by therapy or accidents usually is multifocal - no one lineage is affected preferentially. In this setting, carefully designed combination CSFs are likely to provide the maximum restorative effect. Certain natural states of dysmyelopoiesis, on the other hand, may be corrected by single agents if the defect proves to be lineage or specific to a developmental stage. This appears to be the case in patients with severe congenital neutropenia where G-CSF and sometimes GM-CSF can restore normal myelopoiesis and reverse severe clinical infections. Finally, animal models have shown that antibiotic therapy may be complemented and survival improved with the addition of certain CSFs during ongoing severe bacterial or fungal infections. Early data has also suggested a future role in infection prevention in patients at high risk. This review focuses on the roles of newer CSFs and myeloprotective agents as well as new roles of older CSFs (ie, G- and GM-CSF) in oncology and infectious diseases.

\section{NEW CSFS WITH BROAD CLINICAL POTENTIAL: IL-3 AND IL-6}

Interleukin-3: Until now, CSF clinical development has been restricted to single agents. With the availability of newer, multifunctional agents with diverse CSF activity, combinations are being tested in vitro and in animal models. Primate studies by Donahue et al (15) and Krumwieh et al (16) clearly have demonstrated bi- and tri-lineage proliferation and maturation using IL-3 followed by GM-CSF resulting in significant elevation of

\section{TABLE 1}

Factors available and approved for clinical use

Recombinant human colony-stimulating factors (rhuCSFs)

available and approved for clinical use

Erythropoietin

Granulocyte-CSF

Granulocyte-macrophage-CSF

rhuCSFs in early clinical development

Macrophage CSF

Multi-CSF (interleukin-3)

Interleukin-1

rhuCSFs in animal model testing

Interleukin-6

Interleukin-4

Human stem cell factor

rhuCSFs undergoing in vitro testing

Interleukin-5

Interleukin-7

Interleukin-11

Human granulocyte-macrophage CSF

Human stem cell factor

Interleukin-1 receptor

TABLE 2

States likely to benefit from colony-stimulating factors

latrogenic and other secondary disorders of hematopoiesis

Myelotoxic chemotherapy with or without autologous bone marrow transplant

Radiation accidents

Severe infections

Burns

Renal failure

Drug-induced dysmyelopoiesis

Natural states of dysmyelopoiesis (primary hematopoietic disorders)

Congenital, severe neutropenia

Cyclic neutropenia

Aplastic anemia

Myelodysplastic syndromes

Immunodeficiency syndromes

Acute leukemia

Infection treatment prevention in high-risk states

Asplenic conditions

Hairy cell leukemia

Human immunodeficiency states

Diabetes mellitus

neutrophil and platelet counts compared with either agent alone. In the latter study, the daily administration of IL-3 intravenously for five days followed by daily GM-CSF intravenously for six days resulted in a more rapid rise and earlier peak in peripheral blood neutrophils compared with GM-CSF alone. IL-3 alone produced no response. Reversing the order or concurrent administration is suboptimal or ineffective. Platelet counts also were elevated dramatically with sequential administration compared with IL-3 alone. More recently, a primate study by Winton et al (17) confirmed 
marked multilineage stimulation in marrow and peripheral blood while the primate study of Stahl et al (18) documented megakaryocytic maturation with sequential IL-3 and GM-CSF.

Concurrent with these developments are reports of in vitro multilineage stimulation of bone marrow cells by a novel gene fusion product. Human GM-CSF/IL-3 fusion protein has structural properties of both IL-3 and GM-CSF. Human GM-CSF/IL-3 fusion proteins are recombinant products of the coding regions of human GM-CSF and IL-3 cDNA which are connected by a synthetic linker sequence. Williams and colleagues (10) and subsequently Broxmeyer et al (19) have reported a 10-fold increase in colony-forming units representing early progenitor cells (CFU-GEMM) and burst-forming units-erythroid (BFU-E) colonies on exposure to this product compared with exposure to IL-3 and GM-CSF. These workers suggested that this effect may involve stimulation of different progenitor subsets than those responding to IL-3 or GM-CSF and may involve distinct receptors or receptor affinity. Phase I clinical trials are in progress.

IL-6 in combination with other CSFs: IL-6, another cytokine which may provide further amplification of early progenitor proliferation, is a prototype of newer agents with multifunctional CSF activity and, thus, potentially is useful in many aberrant clinical states. IL-6, originally was identified as a regulator of B cell function (20) and was first reported to act synergistically with IL-3 in 1987 (21) and with GM-CSF in 1989 (22). In the earlier report, Ikebuchi et al (21) cultured murine splenic progenitors in IL-3, IL-6 and both together; the rate of colony formation was enhanced significantly when IL-3 and IL-6 were combined. However, the doubling time of individual colonies was the same in the three groups, with colony growth beginning earlier in the culture with both CSFs. As a result, this interaction has been interpreted in a two-signal model: IL- 6 acts as a competence factor which prepares cells in the $G_{0}$ resting phase of the cell cycle to respond to IL-3 which then acts as a progression factor and induces progenitor cell proliferation. More recently, Takatsuki et al (23) reported that subcutaneous infusion of IL-6 in mice myelosuppressed and immunosuppressed with 5-fluorouracil (5-FU) increased survival compared with controls. Peripheral blood was assessed for increases in antibody titres and cellular response while the spleen and liver were analyzed for infection and cellular infiltration. In the absence of an effect on blood neutrophil counts and a reduction in Escherichia coli cultured from liver and spleen, the workers proposed that locally increased mature neutrophils noted in these organs and the increased antibody titres against $E$ coli may play an important protective role. Unlike neutrophils, however, peripheral blood platelet counts recovered significantly faster. Asano et al (24) have confirmed the dose-dependent nature of platelet increases in primates treated twice daily with subcutaneous IL-6 for 14 days. Other growth factors seem to boost further the effects in these murine models of chemotherapy-induced neutropenia. Rennick and colleagues (25) used the model of 5-FU-treated mice and cultured bone marrow cells for colony growth to show that while IL-6 and IL-3 synergistically stimulate the recovery of increased numbers of multilineage and GM colonies, IL-6 increased only the size (not the number) of GM colonies when combined with GM-CSF. This important study also demonstrated that different combinations of CSFs with IL-6 resulted in varying responses according to time cultured after 5-FU exposure; IL-6 and IL-3 synergistically increased the number of multilineage and GM colonies at two and four days into recovery after 5-FU treatment and IL-6 plus G-CSF or IL-4 enhanced GM colony formation of day 4 but not day 2 cells. Cells cultured on day 8 yielded results similar to those seen with normal cultured marrow cells not exposed to 5-FU (no synergistic effects on colony growth were seen with any combination of IL-6 and other factors, but a shift to megakaryocyte differentiation was seen within colonies exposed to IL-6 and IL-3). IL-6 plus IL-4 significantly augmented lineage-restricted erythroid colonies in the presence of erythropoietin (Epo). Thus, the IL-6 enhancing effect is operative with different CSFs at variable times in colony formation, supporting a global role as a costimulator at different points in hematopoiesis, confirming its role as a thrombopoietin.

In future clinical trials using combination CSFs, timing will be critical with respect to chemotherapy or other therapeutic myelosuppressive interventions. Moreb et al (26) treated human bone marrow cells with 4-hydroperoxycyclophosphamide after exposure to IL6 , IL-3 or IL-1 and cultured cells for CFUs. Whereas IL-1 afforded protection from the colony-suppressive effects of the chemotherapy, IL-6 or IL-3 exposure was associated with a decline in colony function. Pretreatment with IL-1 followed by exposure of cells to IL-3 after chemotherapy yielded the best protection and, thus, the highest colony counts. Neta et al (27) reported an increase in mortality of mice pretreated with IL- 6 before exposure to high dose radiotherapy.

In summary, IL-6 may have a costimulatory role at various times in hematopoiesis, at some points recruiting resting progenitors and/or stimulating proliferation (Figure 1). Independently, IL-6 may act as a thrombopoietin, particularly enhancing this function in the presence of IL-3 by causing a marked shift in ploidy as well as increases in megakaryocyte and platelet counts as shown by Carrington et al (28) and Hill and workers (29) in a murine system. Such a simple explanation, however, is unlikely. Katayama et al (30) found that IL-6 can suppress G-CSF-induced colony formation when added with bone marrow cells at the onset of G-CSF exposure (30). GM-CSF-induced colony formation was not affected. High levels of G-CSF were needed 


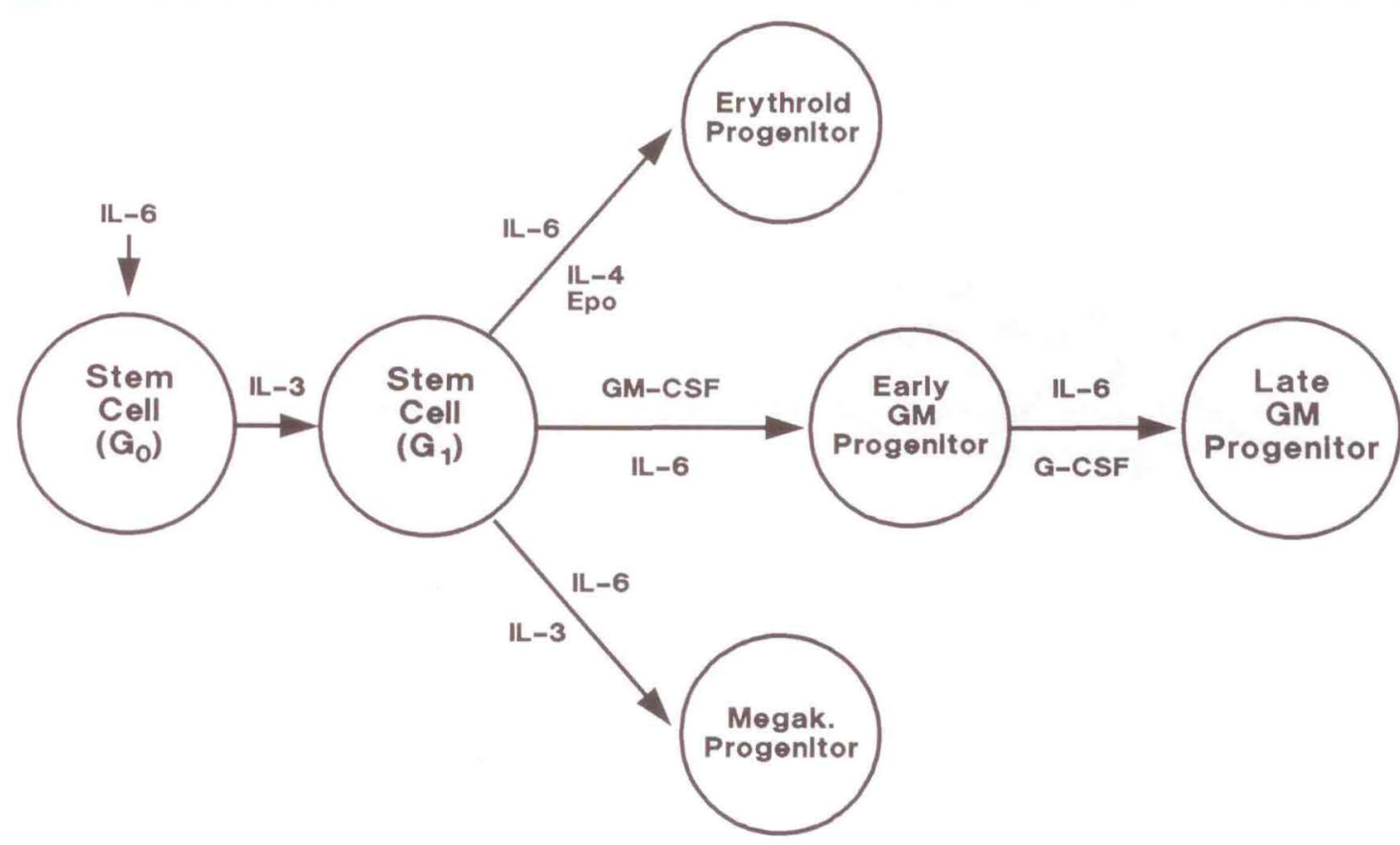

Figure 1) Proposed schema of colony-stimulating factor interactions

to overcome this suppression in the presence of IL-6. Thus, IL-6 may downregulate G-CSF regulator expression in later stages of myeloid development and fulfill yet another regulatory role.

Relevance of IL-6 in other clinical states: IL- 6 may also play a role in the etiology of several pathological conditions of cell growth. Myeloma cells have been shown to produce constitutively IL-6, express its receptors and grow lavishly in its presence (31). The role of IL-6 in the oncogenesis and progression of this disease is being studied. With evidence that specific monoclonal antibodies (MOAbs) against IL-6 can inhibit growth (32), targeted therapy with MOAbs and/or IL-6 receptors could result in a therapeutic breakthrough in this devastating disease. Studying another clinical entity, Brandt et al (33) have developed a murine model which clinically and pathologically mimics Castleman's disease. Characterized by hypergammaglobulinemia and massive multiorgan infiltration by plasma cells and mature granulocytes, this disease was reproduced by the transvection of a retroviral vector bearing the IL-6 gene into murine bone marrow cells. Sustained production of IL-6 correlated with evolution of the disease. Endogenous production of IL- 6 by otherwise clinically benign atrial myxomas has been implicated strongly as the mediator of the polyclonal $\mathrm{B}$ cell activation and the tumour's auto-antibody production, abnormalities which often are cured by surgical removal of the myxoma (34). To round out the picture of IL-6 diversity as a growth factor, IL-6 also has been implicated strongly in the etiology of mesangial proliferative glomerulonephritis (35).

\section{MYELOPROTECTIVE AGENTS: WR-2721 AND IL- 1}

Several new agents have the clinical potential to protect resting bone marrow progenitors from injury and thereby augment the subsequent proliferative recovery after removal of the injurious cause. Thus, while not technically CSFs, these factors can markedly augment CSF's proliferative effects.

WR-2721, or ethiofos, is the prototype of a class of agents known as phosphorothioates (36). Originally developed by the United States army as a protective agent for troops against radiation during nuclear warfare, WR-2721 appears to protect selectively normal tissues from cytotoxicity associated with both radiation and alkylating agents. Its protective properties are due largely to the ability of its active thiol metabolite, WR1065 , to concentrate preferentially in nontumour tissues via facilitated diffusion. This ability has, in turn, been attributed to its hydrophilic structure (37). In early human trials, this agent has been tested in conjunction with platinum analogues for its ability to abrogate several major toxic effects including neuro- and nephrotoxicity as well as myelotoxicity (38).

As for its future role as a myeloprotector, there is growing evidence of its usefulness in conjunction with CSFs. Weiss and colleagues (39) at the Armed Forces Radiobiologic Research Institute have studied the protective effects of WR-2721 in lethally irradiated mice. Since IL-1 alone can act as a radioprotector in mice irradiated up to about $14 \mathrm{~Gy}$, these workers treated mice with cobalt-60 at doses of 14 to $20 \mathrm{G}_{\mathrm{y}}$ and gave WR-2721 and/or IL-1 in different schedules. Whereas IL-1 alone was not protective, treatment with WR-2721 


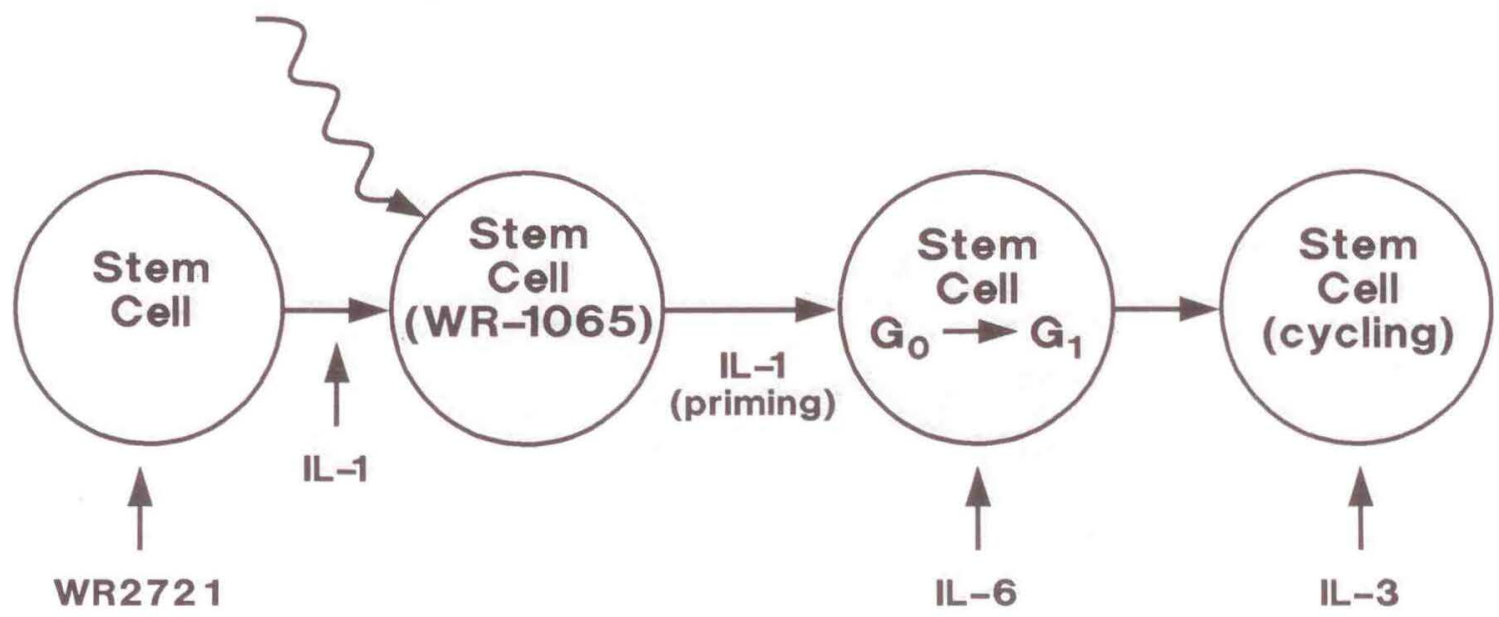

Figure 2) Sequential intervention of radioprotector and colony-stimulating factors

30 mins before irradiation followed by IL- 1 after irradiation yielded the best enhanced survival. Lesser protection was provided when both agents were given together just before irradiation. Weiss et al (39) hypothesized that WR-2721 may act as a true radioprotector without inducing progenitor proliferation.

The role of IL- 1 in this model system is even more intriguing. As mentioned earlier, pretreatment of bone marrow cells with IL-1 results in improved CFU recovery after exposure to cytotoxic chemotherapy. Preexposure to IL-3 results in a marked CFU suppression. A similar protective effect of IL-1 has been described when used prior to exposure of mice to lethal doses of ionizing irradiation and, more recently, when given to hamsters prior to intraperitoneal injection of ${ }^{131} \mathrm{I}$ radiolabelled carcinoembryonic antigen antibody as reported by Blumenthel et al (40). These effects particularly are intriguing because IL-1 has no direct CSF properties; rather, it stimulates by the endogenous release of GM- and G-CSF (41). (Interestingly, the latter two agents can also act as radioprotectors when given prior to radiation [42].) Neta et al (43) have suggested severed mechanisms of radioprotection including reduction in intracellular oxygen in neutrophils, synchronization of progenitors into the relatively radioresistant $S$ phase of the cell cycle and induction of acute phase proteins that can act as free radical scavengers. The timing of IL-1 administration may also be important during progenitor recovery after chemotherapy. Gasparetto and colleagues (44) confirmed the stimulatory properties of $\mathrm{IL}-1$ in primates when daily $\mathrm{IL}-1$ intraperitoneal injections enhanced peripheral blood neutrophils and bone marrow CFU-GM when given for less than seven days beginning $24 \mathrm{~h}$ after 5-FU therapy. Longer periods of IL-1, however, resulted in inhibition of CFU-GM recovery. Well-timed, short exposures of IL-1, therefore, may lead to effective myeloprotection without initiating undesired and morbid side effects.
In summary, WR-2721 and IL-1 appear to act complementary to protect progenitors from radiation death. Properly timed, short exposures of bone marrow progenitors near the time of injury, followed by more sustained exposure to CSFs such as IL-6 and IL-3, may provide a therapeutic one-two punch of myeloprotection and rapid proliferative recovery (Figure 2). A model of an ideal regimen that could restore damaged bone marrow function or provide myeloprotection can be generated for many of the causes of secondary disorders of hematopoiesis listed in Table 2.

\section{INFECTION PREVENTION IN HIGH RISK DISEASE STATES: IN VITRO AND IN VIVO EXAMPLES}

Numerous studies are underway testing the restorative benefits of new CSFs in a variety of diseases where infections are a major morbid and mortal consequence. Already, both GM- and G-CSF are restoring specific defects in severe congenital neutropenia as well as helping to define the variable nature of the defect. Welte et al (45) treated five patients with severe congenital neutropenia with G- or GM-CSF. All patients responded to $\mathrm{G}$-CSF with a marked increase in peripheral neutrophils in excess of $1 \times 10^{9} / \mathrm{L}$; one responded to GM-CSF in this manner while the other four developed eosinophilia. In the presence of elevated endogenous G-CSF, this response points to a defect in CSF responsiveness as an etiological factor. Of most clinical interest was the resolution of an antibiotic-resistant pulmonary pneumonia due to a peptococcus species. In another interesting variation, Ganser et al (46) and Vadhan-Raj et al (47) have described the resolution of chronic infectious or inflammatory lesions with GM-CSF therapy. The correlation of a marked eosinophilic response with healing of such lesions in the absence of a neutrophilic response supports a possible role of eosinophils in normal infection surveillance. Intervention in patients labelled as having severe congenital neutropenia may 
require trials of either of these CSFs or a combination of both to resolve and prevent all lesions associated with the disease. Glasser et al (48) recently have described the use of G- and GM-CSF serum assays as diagnostic guides to therapy in a 12-month-old with severe congenital neutropenia. Unlike the cases of Welte et al (45), this patient had normal GM-CSF levels, but grossly deficient G-CSF levels. Treatment with G$\mathrm{CSF}$ restored the defect. However, the use of such assays may not be helpful if the syndrome is based on a defect of responsiveness at the receptor level as suggested by Moore (49). Another rare neutropenic condition which is being tested for CSF responsiveness is large granular lymphocyte proliferation, a lymphocyte subset disorder characterized by azurophilic granules and natural killer cell antigens. Associated with lymphocyte proliferation is the inhibition of granulocyte progenitors in the bone marrow. de Wolf, Vellenga and others (50) at the University of Groningen in the Netherlands recently have used GM-CSF twice daily to restore granulopoiesis and peripheral blood neutrophil counts to varying degrees in four patients with this disorder.

The usefulness of CSFs in infection prevention in immune deficiency states may soon expand to other deficiencies of immunity. IL-7, for example, enhances accessory cell function of $\mathrm{B}$ cells in the process of antigen presentation (12). IL-4 and IL-5 originally were characterized by their ability to stimulate early B cell progenitor development (20). IL -4 increases class II major histocompatibility complex expression on resting $\mathrm{B}$ cells, promotes immunoglobin (Ig) G and IgE secretion, and induces BFU proliferation; as well, in any of these restorative capacities $\mathrm{IL}-4$ may have a vital and specific role in B cell deficiency disorders (51). The major therapeutic role of IL-4 may be a costimulator of various hematopoietic events. As mentioned earlier, IL-4 stimulates CFU-E in the presence of Epo, but, as Peschel et al (8) have shown, IL-4 can also amplify the proliferation effect of G-CSF, IL-3 or IL-1 on myeloid and megakaryocyte colony formation. Indeed, its potential role appears not unlike IL-6 in this respect. The therapeutic niche of IL-5 will not likely involve B cell function restoration, but rather eosinophil proliferation and may amplify therapeutic regimens against parasitic diseases (52). These recombinant CSFs will accelerate understanding of various inherited immunodeficiency diseases and will restore normal immune function and antimicrobial defences.

\section{AUGMENTATION OF DEFENCES AGAINST ESTABLISHED INFECTIONS}

An area of growing interest for the infectious diseases community is the use of CSFs during ongoing infection. Evidence from several laboratories have suggested that CSFs can augment effector cell function in vitro. In addition to the large body of data on neutrophil augmentation by G- and GM-CSF, Owen et al (53) have reported the improvement of eosinophil function with GM-CSF against Schistosoma mansoni infection. Using semisolid and liquid cultures, Clutterbuck et al (52) found that IL-5, IL-3 and GM-CSF all generated mature eosinophils. Only IL-5, however, selectively stimulated eosinophil production and, as such, must be tested to restore or amplify eosinophil cytotoxicity against parasites. In animal models, Van der Meer et al (54) demonstrated a significant improvement in survival of neutropenic mice infected intraperitoneally with Gramnegative organisms when IL-1 was added to antibiotic therapy. Matsuomoto et al (55) reported similar results using G-CSF in a similar murine model. Patients with autosplenectomy from sickle cell disease, those experiencing therapeutic splenectomy for Hodgkin's disease or recovering from traumatic splenic rupture are more susceptible to encapsulated bacterial sepsis. Hebert et al (56) recently developed a non-neutropenic murine model of Streptococcus pneumoniae pulmonary infection with both splenectomized and sham-operated mice receiving G-CSF. Survival improved only in the splenectomized group; the clearance of live pneumococci from the lungs improved in G-CSF-treated splenectomized and nonsplenectomized mice compared with saline-treated controls. In two clinical reports, GM- and M-CSF have been used to combat invasive fungal infections. Anaissie et al (57) from MD Anderson reported on eight patients with disseminated candidiasis, aspergillosis or trichosporosis in the face of profound neutropenia. Six patients failed to respond to amphotericin B up to a median dose of $600 \mathrm{mg}$. When GM-CSF was given at $400 \mu \mathrm{g} / \mathrm{m}^{2} /$ day, six patients achieved absolute neutrophil counts of at least 1.0x $10^{9} / \mathrm{L}$ after four days. Four of five patients with candidiasis and the patient with trichosporinosis recovered completely. In a more recent report, Nemunaitis et al (6) treated 16 bone marrow transplantation patients with $\mathrm{M}-\mathrm{CSF}$ during invasive fungal infections. Three patients were treated prior to planned bone marrow transplantation and all had infection resolution of sinopulmonary aspergillosis refractory to amphotericin $\mathrm{B}$ and hepatic candidiasis. Ten of 13 post bone marrow transplantation patients experienced clinical and/or radiographic improvement. Interestingly, circulatory myeloid cells remained unchanged. Thus, these studies already are providing evidence of the therapeutic effectiveness of CSFs for otherwise antibiotic refractory mycosis. Mycobacterial and parasitic disease must soon be included in early clinical trials.

\section{IL-9 AND IL-1 1}

At present, IL-9 and IL-11 do not appear to offer any unique activity, but may help direct the specificity of costimulation with other CSFs. IL-9, a T cell-derived cytokine, recently has been characterized as a preferential regulator of early erythropoiesis in conjunction with IL-3 and IL-1 (13). IL-11 now is being characterized and 
appears to synergistically stimulate thrombopoietinlike activity in the presence of IL-3 (14).

\section{CONCLUSIONS}

The challenge of the future will be careful selection of agents for diseases with specific defects and logical combination of CSFs with restorative properties suited for very severe or multiple defects. Factors that determine optimal results will involve dose scheduling and minimization of side effects and undesirable epi-effects. Equally important determinants of entry into standard practice will be patient compliance and acceptability as well as the cost to society.

\section{REFERENCES}

1. Goldberg CB. FDA advisors recommend use of cytokines GM-CSF, G-CSF in BMT and chemotherapy. Cancer Lett $1991 ; 17: 1-5$.

2. Fibbe WE, Schaafsma R, Falkenburg JHF, Wiflemze R. The biological activities of interleukin-1. Blut 1989;59:147-56.

3. Neta R, Oppenhein JJ. Why should internists be interested in interleukin-1? Ann Intern Med 1990;109:1-3.

4. Crown J, Gabrilove J, Kemeny N, et al. Phase I/II trial of recombinant human interleukin-1B (IL-1) in patients with metastatic colorectal cancer receiving 5-fluorouracil (5FU). Proc Am Clin Oncol 1990;9: 183.

5. Ganser A, Lindemann A, Seipelt G, et al. Effects of recombinant human interleukin-3 in patients with normal hematopoiesis and in patients with bone marrow failure. Blood 1990;76:666-76.

6. Nemunaitis J, Meyers JD, Buckner CD, et al. Phase I/II trial of recombinant human macrophage colonystimulating factor (M-CSF) in patients with invasive fungal infection. Annual Meeting of the American Society of Hematology. Blood 1990;76:159a.

7. Takatsuki F, Okano A, Suzuki C, et al. Interleukin-6 profusion stimulates reconstitution of the immune and hematopoietic systems after 5-fluorouracil treatment. Cancer Res 1990;50:2885-90.

8. Peschel C, Paul WE, Ohara J, Green I. Effects of B-cell stimulatory factor-1/interleukin-4 on hematopoietic progenitor cells. Blood 1987;70:254-63.

9. Andrews RG, Bartelmez SH, Egrie J, et al. Recombinant human stem cell factor (rhSCF) stimulates in vitro and in vivo hematopoiesis in baboons. Blood 1990;76:130a.

10. Williams DE, Broxmeyer HE, Curtis BM, et al. Enhanced biological activity of a human GM-CSF/IL-3 fusion protein. Exp Hematol 1990; 18:615.

11. Clutterbuck EJ, Hirst AMA, Sanderson CJ. Human interleukin-5 (I]L-5) regulates the production of eosinophils in human bone marrow cultures: Comparison in interaction with IL-1, IL-3, IL-6, and GM-CSF. Blood 1989;73:1504-12.

12. Dennig D, O'Reilly RJ. Interleukin-7 (IL-7) enhances B cell accessory function. Blood 1990;76:204a.

13. Ottmann OG, Ganser A, Eder M, et al. Stimulatory effects of recombinant human interleukin-9 (IL-9) on bone marrow-derived erythroid progenitors in serum-free culture: Synergism with IL-3 and IL-1. Blood 1990;76:159a.

14. Larson D, Leary A, Hahn-Cordes L, et al. Interleukin-11 (IL-11) synergizes with IL-3 in promoting human and murine megakaryocyte colony formation in vitro. Blood 1990;76:464a.
15. Donahue RE, Seehra J, Metzger M, et al. Human IL-3 and GM-CSF act synergistically in stimulating hematopoiesis in primates. Science 1988;241:1820-3.

16. Krumwieh D, Weinmann E, Seiler FR. Human recombinant derived $\mathrm{IL}-3$ and GM-CSF in hematopoiesis of normal cynomolgous monkeys. Behring Inst Mitt 1988;83:250-7.

17. Winton EF, Rozmiarek SK, Jacobs PC, et al. Marked increase in marrow and peripheral blood multi-lineage and megakaryocyte progenitor cells induced in shortcourse sequential recombinant human IL-3/GM-CSF in a non-human primate. Blood 1990;76:172a.

18. Stahl CP, Winton EF, Munroe MC, et al. Sequential recombinant human IL-3 and rhGM-CSF stimulates megakaryocyte maturation and increases platelet counts in non-human primates. Blood 1990;76:477a.

19. Broxmeyer AG, Cooper S, Shen FW, et al. Characteristics of human $\mathrm{CD}_{4} 5^{+}$hematopoietic progenitor cells stimulated by a human GM-CSF/IL-3 fusion protein and responsiveness to suppressor cytokines. Blood 1990;76:134a.

20. Kishimoto T. The biology of interleukin-6. Blood 1989;75:1-10.

21. Ikebuchi K, Wong GG, Clark SC, et al. Interleukin-6 enhancement of interleukin-3-dependent proliferation of multipotential hematopoietic progenitors. Proc Natl Acad Sci USA 1987;84:9035-9.

22. Caracciolo D, Clark SC, Rovera G. Human interleukin-6 supports granulocytes differentiation of hematopoietic progenitor cells and acts synergistically with GM-CSF. Blood 1989;73:666-70.

23. Takatsuki F, Okano A, Suzuld C, et al. Interleukin-6 perfusion stimulates reconstitution of the immune and hematopoietic systems after 5-fluorouracil treatment. Cancer Res 1990;50:2885-90.

24. Asano S, Okano A, Ozawa $\mathrm{K}$, et al. In vivo effects of recombinant human interleukin-6 in primates: Stimulated production of platelets. Blood 1990;75:1602-5.

25. Rennick D, Jackson J, Yang G, et al. Interleukin-6 interacts with interleukin-4 and other hematopoietic growth factors to selectively enhance the growth of megakaryocytic, erythroid, myeloid, and multipotential progenitor cells. Blood 1989;73:1828-35.

26. Moreb J, Zucali JR, Weiner RS. The role of interleukin-3 and interleukin- 6 in the protection from 4-hydroperoxycyclophosphamide and the proliferation of early human hematopoietic progenitor cells. Exp Hematol 1989; 17:1022-7.

27. Neta R, Vogel SN, Sipe JD, et al. Comparison of in vivo effects of human recombinant IL-1 and human recombinant IL-6 in mice. Lymphokine Res 1988;7:403-6.

28. Carrington $\mathrm{BA}$, Hill $\mathrm{RJ}$, Stenberg $\mathrm{P}$, et al. Multiple in vivo effects of interleukin-3 and interleukin-6 in murine megakaryocytopoiesis. Blood 1991;77:34-41.

29. Hill RJ, Warren MK, Stenberg P, et al. Stimulation of megakaryocytopoiesis in mice by human recombinant interleukin-6. Blood 1991;77:42-8.

30. Katayama K, Koizumi S, Ueno Y, et al. Antagonistic effect of interleukin-6 and G-CSF in the later stage of human granulopoiesis in vitro. Exp Hematol 1990;18:390-4.

31. Kwano M, Hirano T, Matsuda T, et al. Autocrine generation and essential requirement of BSF-2/IL-6 for human multiple myelomas. Nature 1988;332:83-5.

32. Kawano M, Kuramoto A, Hirano T, Kishimoto T. Cytokines as autocrine growth factors in malignancies. Cancer Surv 1989;8:905-19.

33. Brandt SJ, Bodine DM, Dunbar CE, Nienhuis AW Dysregulated interleukin-6 expression produces a 
syndrome Castleman's disease in mice. Blood 1989;74:48a.

34. Sutton MGSJ, Mercier L, Giuliani ER, Lie JT. Atrial myxomas: A review of clinical experience in 40 patients. Mayo Clin Proc 1980;55:371-4

35. Horii Y, Mureguchi A, Iwano M, et al. Involvement of IL-6 in mesangial proliferative glomerulonephritis. J Immunol 1989;143:3949-55.

36. Gandara DR, Wiebe VJ, Perey EA, Makuch RW, DiGregorio MW. Cisplatin rescue therapy: Experience with sodium thiosulfate, WR2721, and diethyldithiocarbamate. Crit Rev Oncol Hematol 1990;10:353-65.

37. Yuhas JM, Davis ME, Glover D, et al. Circumvention of tumor membrane barrier to WR-2721 absorption by reduction of drug hydrophilicity. Int $\mathrm{J}$ Radiat Oncol Biol Phys 1982;8:519-22.

38. Glover D, Glick JH, Weiler C, et al. Y-IR-2721 and high-dose cisplatin: An active combination in the treatment of metastatic melanoma. J Clin Oncol 1987;5:574-8.

39. Weiss JF, Kuman KS, Neta R. Enhancement of the radioprotective effect of WR-2721 with IL-1 in mice. Proceedings of a Symposium on Combining Biological Response Modifiers with Cytotoxics in the Treatment of Cancer 1990:24. (Abst)

40. Blumenthal RD, Sharkey RM, Quirm LM, Goldenberg DM. Use of hematopoietic growth factors to control myelosuppression caused by radioimmunotherapy. Cancer Res 1990;50:1003s-7s.

41. Dinarello CA. Interleukin-1 and interleukin-1 antagonism. Blood 1991;77:1627-52.

42. Waddick KG, Song CW, Souza L, Uckun FM. Comparative analysis of the in vivo radioprotective effects of recombinant granulocyte colony-stimulating factor (G-CSF), recombinant granulocyte-macrophage CSF, and their combination. Blood 1991;77:2364-71.

43. Neta R, Douches S, Oppenheim JJ. J Immunol 1986:136:2483-5.

44. Gasparetto C, Laver J, Abboud M, et al. Effects of interleukin-1 on hematopoietic progenitors: Evidence of stimulatory and inhibitory activities in a primate model. Blood 1989;74:547-50.

45. Welte K, Zeidler C, Reiter A, et al. Differential effects of granulocyte-macrophage colony-stimulating factor and granulocyte colony-stimulating factor in children with severe congenital neutropenia. Blood 1990;5:1056-63.

46. Ganser A. Ottmann OG, Erdmann H, et al. The effect of recombinant human granulocyte-macrophage colony- stimulating factor on neutropenia and related morbidity in chronic severe neutropenia. Ann Intern Med 1989;111:887-92.

47. Vadhan-Raj S, Jeha SS, Buescher S, et al. Stimulation of myelopoiesis in a patient with congenital neutropenia: Biology and nature response to recombinant human granulocyte-macrophage colony-stimulating factor. Blood 1990;75:858-64.

48. Glasser L, Duncan BR, Corrigan JJ. Use of serum G-CSF and GM-CSF levels in the diagnosis of neutropenias: A case study. Blood 1990;76:145a.

49. Moore MAS. Clinical implications of positive and negative hematopoietic stem cell regulators. Blood 1991;78:1-19.

50. de Wolf JTHM, Mulder AB, Smit JW, Vellenga E. Correction of neutropenia by GM-CSF in patients with large granular lymphocyte proliferation. Blood 1990;76:139a.

51. Noelle R, Kramma PH, Ohara J, et al. Increased expression of Ia antigens on resting B cells: An additional role of B-cell growth factor. Proc Natl Acad Sci USA 1984;81:6149.

52. Clutterbuck EJ, Shields JG, Gordon J, et al. Recombinant human interleukin-5 is an eosinophil differentiation factor but has no activity in standard human B cell growth factor assays. Eur J Immunol 1987; $17: 1743-8$.

53. Owen WF, Rothenberg ME, Silberstein DS, et al. Regulation of human eosinophil viability, density, and function by granulocyte-macrophage colony-stimulating factor in the presence of three T3 fibroblasts. J Exp Med 1987; 166:129-41.

54. van der Meer JW, Barza M, Wolff SM, Dinarello CA. A low dose of recombinant interleukin-1 protects granulocytopenic mice from lethal gram-negative infection. Proc Natl Acad Sci USA 1988;85:1620-3.

55. Matsumoto M, Matsubara S, Matsuno T, et al. Protective effect of human granulocyte colony-stimulating factor on microbial infection in neutropenic mice. Infect Immun 1987:55:2715-20.

56. Hebert JC, O'Reilly M, Gamelli RL. Protective effect of recombinant human granulocyte colony-stimulating factor against pneumococcal infections in splenectomized mice. Arch Surg 1990;125:1075-8.

57. Anaissie E, Bodey GP, Obrien S, et al. Effect on granulocyte-macrophage colony-stimulating factor on myelopoiesis and disseminated mycoses in neutropenic patients with hematologic malignancies. Blood 1989;74:15a. 


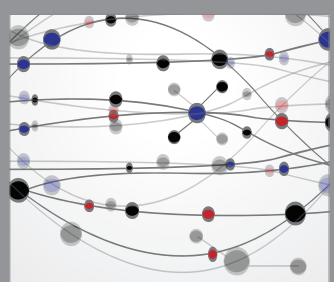

The Scientific World Journal
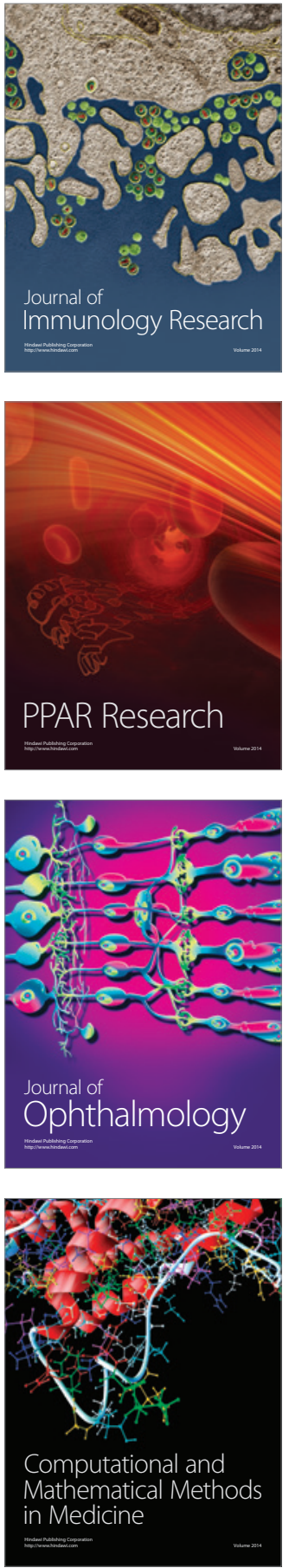

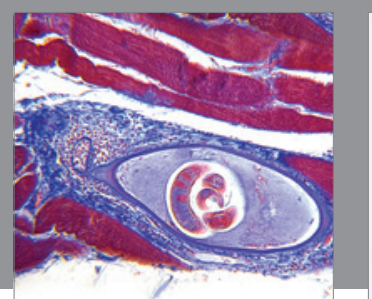

Gastroenterology Research and Practice

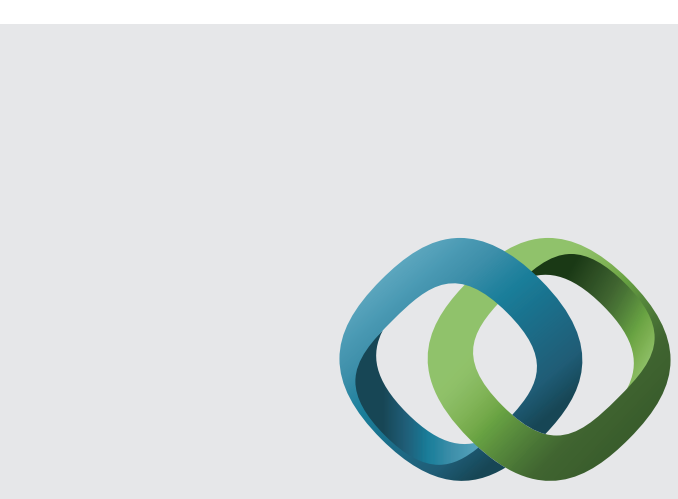

\section{Hindawi}

Submit your manuscripts at

http://www.hindawi.com
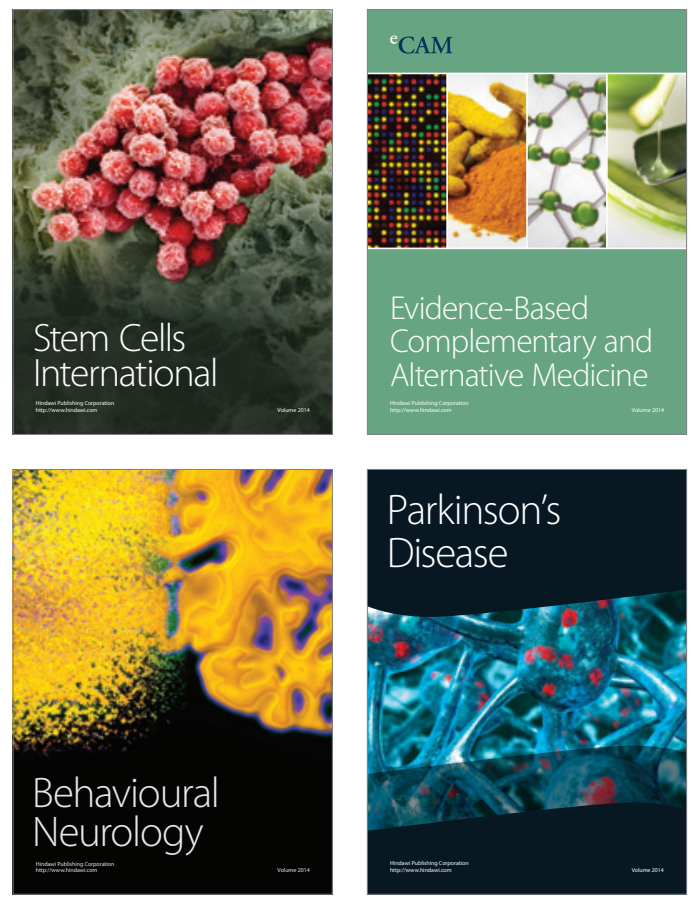
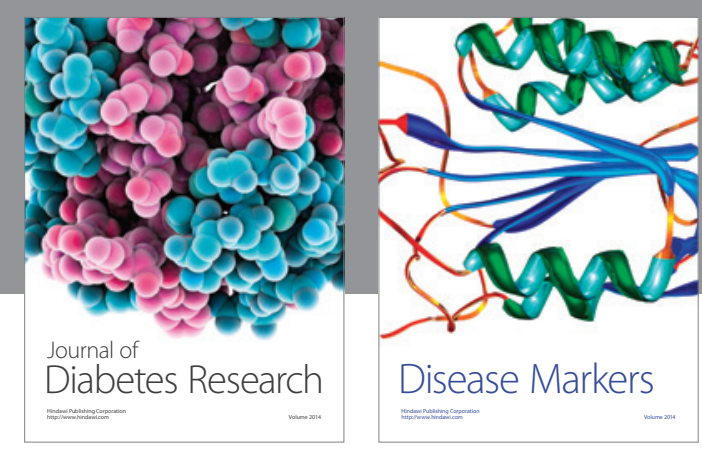

Disease Markers
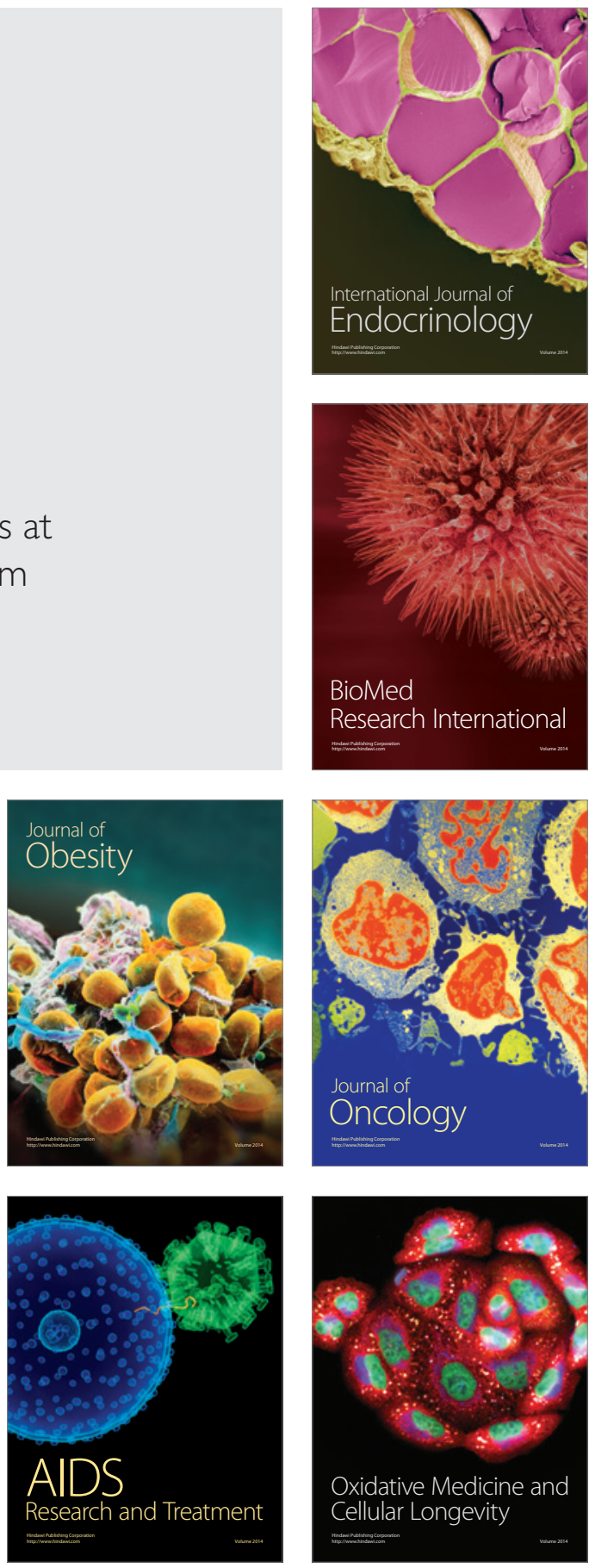